\section{Molecular genetics of cancer}

\author{
B A J Ponder
}

This is the first in a series of articles examining recent developments in cancer.

\section{Cancer as a genetic disease}

Several steps are needed to turn a normal cell into a cancer cell. Most, if not all, of these include mutational change. Cancer is therefore a genetic disease at the level of the cell. It may also be a genetic disease at the level of inheritance. Many of the "cancer genes" have important normal functions in the control of growth and development. The rapidly growing understanding of the genetics of cancer is leading in two directionstowards new approaches to treatment and prevention and towards a deeper insight into the central problems of cell biology.

\section{ACCUMULATION OF MUTATIONS IN A CELL}

Most cancers start from a single cell. This cell and its descendants must have accumulated mutations in several different genes before they become cancer.' Some of the later stages of this accumulation may be reflected in abnormal behaviour of the cell and be recognised by the pathologist as increasing degrees of premalignant change, such as dysplasia. However, we have not yet generally reached the point where specific pathological features can be related to mutation in specific genes.

Mutations in tissue cells accumulate continually throughout life, beginning in the embryo. As we grow older, each of us is an increasingly complex mosaic of mutant cells and their progeny. Whether in any one of us a complete set of critical mutations coincides within the same cell and leads to cancer depends, no doubt, on luck; but it also depends on the environmental, behavioural, and inherited factors that determine whether our cells are exposed to potential mutagens and how we deal with the consequences. In other words, cancer risk depends not only on environmental exposure but also on genetic make up. In a few people the inherited factor is particularly strong. In the race to accumulate mutations, these people have a head start because they have already inherited a critical mutation in every cell, through the germline. They, and their family members who have inherited the same mutation, are much more likely to develop cancer and may be recognisable as part of a "cancer family.",

\section{Critical genes}

Most cancer genes that have been identified so far belong to one or another of the chains of command within the cell for the control of growth or differentiation (table I). Conceptually, they fall into two groups: oncogenes, ${ }^{3+}$ mutations of which lead to altered activity

TABLE I - Examples of oncogenes and suppressor genes and their role in pathways of cellular growth control ${ }^{\star}$

\section{Cancer Research}

Campaign Human Cancer Genetics Research Group, Department of Pathology, University of Cambridge, Cambridge CB2 1QP

B A J Ponder, director

Series edited by: Dr G M Mead.

BMf 1992;304:1234-6

${ }^{\star}$ Growth control molecules outside the cell act by binding to cell surface receptors. The signals are relayed from the inner surface of these receptors across the cytoplasm to the nucleus, where they affect DNA replication or gene expression. Many of the genes which are mutated in cancer cells or are implicated in inherited predisposition to cancer lie at one another on these control pathways.

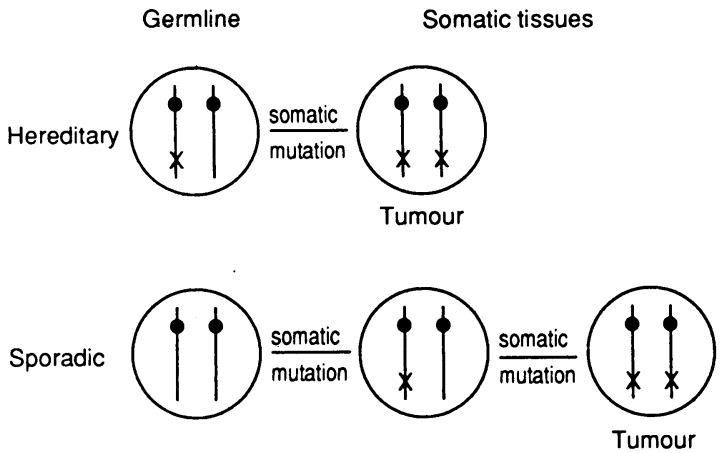

FIG 1-Knudson's hypothesis. The two chromosomes of a pair are shown with mutation $(X)$ at the locus of a cancer gene. Whereas only one further (somatic) mutation is required for tumour formation in hereditary cases, two mutations within the same cell are required in sporadic cases

or increased expression of the corresponding protein, which has a positive effect in driving the cell towards malignancy, and suppressor genes, ${ }^{5}$ mutations of which result in loss of activity or expression of the corresponding protein, and thereby loss of a normal function of regulation or restraint. Not surprisingly, the types of mutation which activate oncogenes or lose activity of suppressor genes tend to be different.

\section{ONCOGENES}

Oncogenes may be activated by a change in a single amino acid, leading, for example, to an altered shape of the protein; by multiplication of the gene within the chromosome to provide several copies and thus increased activity (amplification); or by rearrangements of genes between chromosomes so that functional regions of the oncogene are brought under different and inappropriate control. The first oncogenes were identified by experiments in which DNA from cancer cells was broken into small pieces and introduced into mouse fibroblasts in culture. The presence of activated oncogenes caused the mouse cells that received them to grow abnormally, and it was fairly straightforward to isolate these "transformed" cells and identify the human DNA sequences within them that were responsible. Subsequently, other oncogenes have been identified by their presence at the points of critical chromosome rearrangements in cancers - for example, the abl gene, which is activated by the chromosome 9-22 rearrangement in chronic myeloid leukaemia.

\section{SUPPRESSOR GENES}

Suppressor genes are more difficult to find because it is much more difficult to set up an assay to look for a negative activity. The existence of suppressor genes was predicted over 20 years ago by Knudson. ${ }^{6}$ Figure 1 shows the hypothesis he proposed to account for the observation that hereditary and sporadic cases of retinoblastoma are histologically and clinically indistinguishable but that the hereditary cases occur on average earlier and are often multiple. The hypothesis states that both copies of a critical gene must be lost from a cell for a tumour to develop. In hereditary cases one loss is inherited as a mutation in the germline and is therefore already present in every cell in the target tissue. In this case, the chances are very high that loss 
of the second copy will subsequently occur by mutation in at least one cell of the tissue, and one or several tumours will almost certainly result. In sporadic cases, by contrast, both mutations have to occur by chance as somatic mutations in the same cell. This coincidence will be rare, so sporadic tumours will be uncommon (in retinoblastoma, about 1 in 100000 children) and on average they will take longer to occur; multiple tumours in the same child will be so unlikely as to be almost diagnostic of an inherited predisposition. Ten years after this hypothesis the germline retinoblastoma $(\mathbf{R b})$ mutation was located on chromosome 13, and shortly after that Knudson's hypothesis was confirmed by the finding that in retinoblastoma tumours both copies of the $\mathrm{Rb}$ gene were indeed inactivated by mutation. ${ }^{7} \mathrm{~A}$ similar genetic mechanism probably underlies the other inherited cancer syndromes such as familial polyposis of the colon, multiple endocrine neoplasia, and neurofibromatosis.

Although the idea of suppressor genes was developed from studies of inherited cancers, their importance is not confined to these cases. The role of suppressor gene mutations in sporadic cancers has been shown by studies of so called "allele loss" or "loss of heterozygosity" (fig 2). The principle is straightforward. The mutational event which results in loss of the second copy of the gene is often accompanied by a large scale chromosomal rearrangement or deletion. Because it is a large scale event, this is relatively easy to detect by using sets of DNA markers which have two alleles,

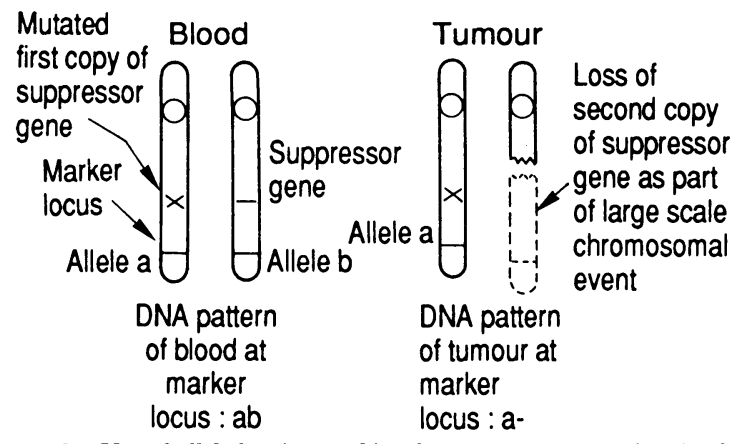

FIG 2-Use of allele loss in searching for suppressor genes. A pair of chromosomes which carry a locus for a suppressor gene is shown. Loss of the second copy of the suppressor gene is accompanied by large scale loss of chromosomal material from that region, which is detected as loss of one allele (b) at a marker locus on the chromosome

TABLE II-Chromosomal locations of probable tumour suppressor genes acting in some common cancers

\begin{tabular}{ll}
\hline Cancer & \multicolumn{1}{c}{$\begin{array}{c}\text { Chromosomal region } \\
(\mathrm{p}=\text { short arm, q=-long arm) }\end{array}$} \\
\hline Breast & 1p 1q 3p 6q 11p 13q 16q 17p 17q 1822 \\
Colorectal & 1p 5q 17p 18q 22 \\
Small cell lung cancer & 3p 11p 13q 17p \\
Glioma & 9p 10 17p 22q \\
Prostate & 8p 10q 16q \\
Renal & 3p 5q 10 13q 18
\end{tabular}

Note that some regions are often involved, which suggests that losses of some suppressor genes may be common to the development of many different cancers. However, some chromosome regions (for example, $3 \mathrm{p}$, $17 p, 17 q$ ) probably contain several different suppressor gene loci.

TABLE III - Examples of associated abnormalities in inherited cancer syndromes

\begin{tabular}{lll}
\hline Syndrome & Tissues principally affected by tumour & Characteristic associated abnormalities \\
\hline Familial adenomatous polyposis & Colon (small intestine, thyroid, liver) & $\begin{array}{c}\text { Multiple colonic polyps, hypertrophy of } \\
\text { retinal pigment epithelium, desmoid } \\
\text { tumours }\end{array}$ \\
Von Hippel-Lindau disease & $\begin{array}{c}\text { Kidney, adrenal medulla, } \\
\text { haemangioblastoma of cerebellum } \\
\text { Neurofibromatosis type 1 }\end{array}$ & $\begin{array}{l}\text { Glia, adrenal medulla, Schwann cells retina, multiple cysts of } \\
\text { internal organs } \\
\text { Multiple: including café au lait spots, } \\
\text { cutaneous neurofibroma, scoliosis, } \\
\text { axillary freckling, short stature } \\
\text { Dyplacal (large, irregular, unusually } \\
\text { pigmented) naevi }\end{array}$ \\
\hline
\end{tabular}

Features that may suggest the presence of inherited predisposition

1 Uncommon cancers in two or more close blood relatives

2 Common cancer at a young age ( $<45$ years) in close blood relatives

3 Bilateral or multiple primary cancers

4 Associated non-cancerous abnormalities: Developmental abnormalities (see table III) Marker phenotypes - colon cancer with multiple polyps, melanoma with atypical naevi

each allele being present in one of the chromosomes of a pair. DNA from the tumour is compared with DNA from the patient's blood. The consistent loss of one allele of the pair in a particular chromosomal region in the tumour DNA strongly suggests that loss of genes from this region is a necessary feature of tumour development, and it implies the presence in that region of one or more suppressor genes (table II). Many laboratories worldwide are now trying to identify the specific genes involved.

Like the $\mathrm{Rb}$ gene, some of these genes may be the targets of inherited mutations in the inherited cancer syndromes, as well as having a role in the development of sporadic tumours. Thus, the detailed analysis of allele losses in common colon cancers pinpointed the location of the familial polyposis gene on chromosome 5 , and a similar strategy is being used to find the other genes responsible for inherited breast and ovarian cancer. Other suppressor genes seem to act only through somatic mutations as part of tumour development, perhaps because these mutations would be lethal to the development of the embryo if they were inherited.

\section{Inherited predisposition to cancer}

Perhaps $5-10 \%$ of common cancers (breast, ovarian, colon) occur in familial clusters which are the result of genetic susceptibility. ${ }^{89}$ Relatives in some of these families may have lifetime risks of specific cancers as high as $30-40 \%$. The problem, of course, is that cancer is a common disease and so some family clusters may be simply due to chance. Because of this, family histories are often ignored. If there is a very strong family history, as in the example in figure 3 , genetic predisposition is in little doubt. Less striking family histories may be more difficult to identify, and the box lists some family histories that are likely to be important. A characteristic phenotype caused by the inherited gene mutation provides unambiguous recognition of some of the inherited cancer syndromes (table IV), and should be searched for even in isolated cases of these tumours in young people. The clinical implications will be discussed below.

Predisposition in these families is usually due to a single dominantly inherited gene, which means that the child of an affected parent is at $50 \%$ risk of inheriting the predisposition. However, the chances that the gene will result in cancer may vary both within and between families and will be related to age, so that the risk to an individual will usually be spread over many years and some carriers of the gene may never develop the cancer at all. In multiple case families, it is possible to search for the predisposing genes by genetic linkage. ${ }^{10}$ The inheritance of a series of marker genes through the family is studied until a marker is found, the inheritance of which coincides with that of the cancer. The cancer gene and the marker gene must lie close together on a chromosome, otherwise their inheritance would become separated by genetic crossing 
over in each generation. The recent rapid development of the human gene map has provided many hundreds of gene markers, and as a result many of the genes for the more striking familial cancers have already been located (table IV). To move from this mapping of a gene to the isolation of the gene itself is a laborious process, but five such genes have now been found, each of which seems to have a normal function in some aspect of the control of cell proliferation or differentiation. More will certainly follow.

Progress has been made with the clear cut inherited cancer syndromes such as familial polyposis because the genetic predisposition is strong and therefore relatively well defined and easy to analyse. It is important to realise, however, that in cancer (as in other common diseases with an inherited component, such as atherosclerotic heart disease) such extreme effects account for only a small part of the population burden of the disease. There are almost certainly many commoner predisposing genes which have weaker effects, so that even in a gene carrier the risk of the specific cancer may be only (say) $10 \%$. These genes will be hard to spot because there will be hardly any familial clustering: most people in the family who have inherited the gene will not have cancer. Even so, it is easy to show that at the population level the genes could result in most of the cases of a specific cancer occurring within a predisposed minority of the population. ${ }^{8}$ If true, this has obvious implications for screening and prevention. Interactions between genes and the environment may also be important. Evidence is already emerging, for example, that the risk of lung cancer from cigarette smoking is higher in a genetically predisposed group within the population. "Because genetic predisposition is likely to affect many more people than the clear cut family cancer syndromes, in the long term it may be of much greater importance for public health.

\section{Clinical implications \\ INHERITED PREDISPOSITION}

Some familial cancers offer the opportunity to identify people at high risk to enable screening or prevention. For example, families with the dysplastic naevus syndrome may be at very high risk of melanoma. ${ }^{12}$ They should protect their children from sunburn, and from puberty onwards family members should have regular checks and excision of suspicious naevi. An apparently isolated case of haemangioblastoma of the cerebellum may have occurred in someone coming from a family with von Hippel-

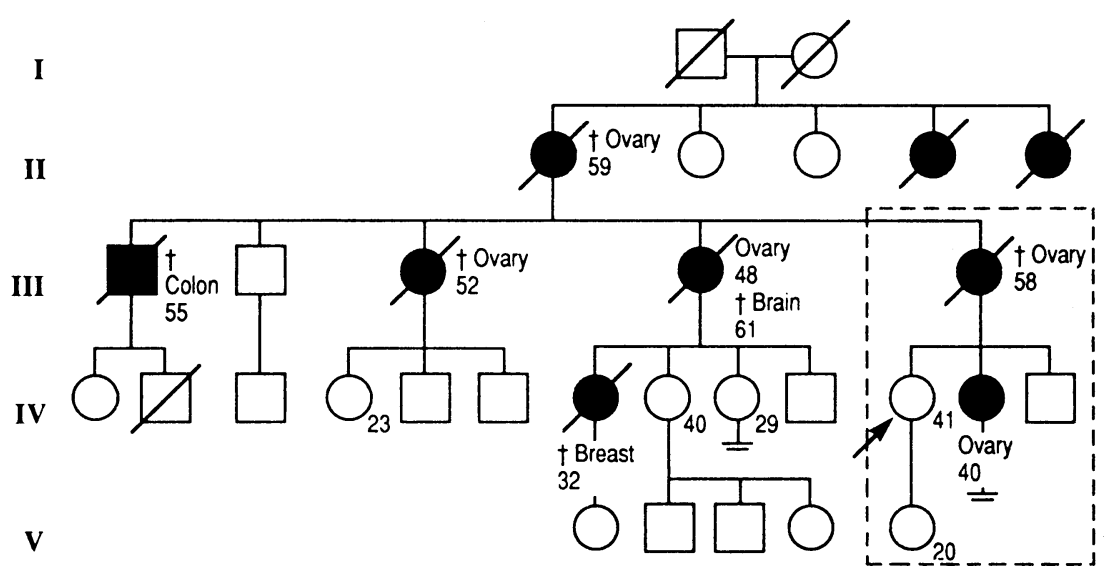

FIG 3-Pedigree of family with ovarian, breast, and colon cancer. The 41 year old woman (arrowed) in generation IV sought advice. Her history was of an affected sister and mother (dotted rectangle) which is suggestive of predisposition. Further investigation of family history provided stronger evidence and indicated other family members at risk (indicated by age)
TABLE IV-Localisation of some inherited genes predisposing to cancer

\begin{tabular}{lc}
\hline Cancer & Chromosome \\
\hline Colon (familial adenomatous polyposis) & $5 \mathrm{q}$ \\
Breast (also families with breast and ovarian cancer) & $17 \mathrm{q}$ \\
Pituitary, adrenal, pancreatic islets (multiple endocrine & \\
$\quad$ neoplasia type I) & $11 \mathrm{q}$ \\
Thyroid C eail, phaeochromocytoma (multiple endocrine & \\
$\quad$ neoplasia type II) & 10 \\
Kidney (von Hippel-Lindau disease) & $3 \mathrm{p}$ \\
Glioma (neurofibromatosis type 1) & $17 \mathrm{q}$ \\
Retina, bone (retinoblastoma, osteosarcoma) & $13 \mathrm{q}$ \\
\hline
\end{tabular}

Lindau disease. Such families are at risk of kidney cancer in middle age and will probably benefit from screening. ${ }^{13}$ These conditions are uncommon, but if family histories are not taken opportunities will be lost. The families themselves are usually already aware that something is amiss and will welcome advice. Of course, there are difficult cases. The significance of the family history may not be clear (is the occurrence of breast cancer in two sisters at age 45 important?) or it may not be clear who will benefit from genetic advice (is breast cancer screening worth while in young women?). Population based epidemiological studies are providing the answers to questions of the importance of a given family history (for example, there is about a $70 \%$ probability that breast cancer at age 45 in two sisters is due to predisposition, rather than chance). How the genetic information should be used requires careful evaluation in research studies by groups of centres with a special interest. The non-expert clinician faced with such a family should seek the advice of a clinical geneticist.

\section{GENETIC CHANGES WITHIN TUMOURS}

The behaviour of a cancer must presumably be governed by the sum of genetic changes that it contains. It is to be hoped, therefore, that a genetic profile of the tumour will eventually provide a more complete diagnosis and prognosis than conventional pathology. The predictive value of some genetic changes has already been shown-for example in neuroblastoma, where tumours in which the myc oncogene is amplified are more likely to be disseminated and have a poor prognosis, and in breast cancer where amplification of the oncogene erb B2 (her2 or neu) and loss of heterozygosity on chromosome 7 are each associated with worse prognosis. ${ }^{14}$ The next challenge will be to move from description to the exploitation of these mutant genes as specific targets for cancer treatment.

1 Nowell PC. Clonal evolution of tumour cell sub-populations. Science 1976;194:23.

2 Genetics and cancer, I and II. In: Cavenee WK, Ponder B, Solomon E, eds. Cancer surveys. Vol 9. Genetic predisposition to cancer. Oxford: Oxford University Press, 1991.

3 Bishop JM. Molecular themes in oncogenesis. Cell 1991;64:235-48.

4 Aaronson SA. Growth factors and cancer. Science 1991;254:1146-53.

5 Weinberg RA. Tumour suppressor genes. Science 1991;254:1138-46.

6 Knudson AG. Mutation and cancer: statistical study of retinoblastoma. Proc Natl Acad Sci USA 1971;68:820.

7 Ponder BAJ. Gene losses in human tumours. Nature 1988;335:400.

8 Easton DF, Peto J. The contribution of inherited predisposition to cancer incidence. In: Cavenee WK, Ponder B, Solomon E, eds. Cancer surveys. Vol 9.Genetic predisposition to cancer. Oxford: Oxford University Press, Vol 9.Genetzc pre

9 Ponder BAJ. Genetic predisposition to cancer. Br f Cancer 1991;64:203-4.

10 Ott J. A short guide to linkage analysis. In: Davies KE, ed. Human genetic disease: a practical approach. Oxford: IRL Press, 1986

11 Nakachi K, Imai K, Hyashi S-I, Watanabe J, Kawajiri K. Genetic susceptibility to squamous cell carcinoma of the lung in relation to cigarette smoking dose. Cancer Res 1991;51:5177-80.

12 Greene MH, Clarke WH, Tucker MA, Elder DE, Kraemer KH, Guerry D IV et al. Acquired precursors of cutaneous malignant melanoma on the familia dysplastic naevus syndrome. $N$ Engl I Med 1985;312:91-7.

13 Maher ER, Yates JEW. Familial renal cell carcinoma: clinical and molecular genetic aspects. Br $\mathcal{F}$ Cancer 1991;63:176-9.

14 Bieche I, Champeme MH, Matifas F, Hacene K, Callahan R, Lidereau R. Loss of heterozygosity on chromosome $7 \mathrm{q}$ and aggressive primary breast cancer. Lancet 1992;339:139-43. 